\title{
PEMBENTUKAN IDENTITAS BUDAYA REMAJA DARI KELUARGA PERNIKAHAN BEDA BUDAYA
}

\author{
Yulia Citra Dewi, Wenny Widyowati \\ Prodi Manajemen Komunikasi Fakultas Ilmu Komunikasi Universitas Padjadjaran
}

\begin{abstract}
ABSTRAK
Pernikahan antarpasangan yang berbeda budaya dapat melahirkan keluarga dengan budaya yang berbeda.Tujuan penelitian ini adalah untuk mengetahui proses pembentukan identitas budaya remaja dan pemilihan bahasa remaja dari keluarga pernikahan beda budaya. Metode yang digunakan adalah kualitatif dengan pendekatan fenomenologi. Teknik pengumpulan data yang digunakan adalah observasi, dan wawancara mendalam dengan tujuh orang subjek penelitian dilengkapi dengan studi dokumentasi dan kepustakaan. Hasil penelitian ini adalah bahwa lingkungan di mana seseorang tinggal mempengaruhi pembentukan identitas budayanya. Proses pembentukan identitas budaya informan yang pernah menetap di lingkungan salah satu budayanya menunjukkan perbedaan dengan informan yang pernah menetap di kedua lingkungan budaya serta informan yang tidak pernah menetap di lingkungan kedua kebudayaannya. Sedangkan perkembangan bahasa anak dipengaruhi oleh komunikasi dalam keluarga dan dalam lingkungan dimana anak tersebut berinteraksi. Simpulan penelitian ini adalah bahwa kebudayaan dipelajari dan diajarkan ketika manusia berada dalam lingkungan budaya dan beriteraksi dengan orang-orang dari dalam lingkungan kebudayaannya. Jadi identitas budaya dan perkembangan bahasa dipengaruhi oleh lingkungan tempat seseorang tinggal.

Kata Kunci: identitas budaya, bahasa remaja, pernikahan beda budaya
\end{abstract}

\section{THE FORMATION PROCESS OF ADOLESCENTS CULTURAL IDENTITY FROM FAMILY BY MARITALWITH DIFFERENT CULTURE}

\begin{abstract}
The purpose of this research is to find out the formation process of cultural identity of adolescents and language selection of adolescent in a family by marital with different culture. The methods used in this research is qualitative with fenomenology aproach. The data colecting technique used are observation and depht interview with seven informants, and document studies. As results of this research, it is shown that the environment in which ones lives affects the formation process of cultural identity. The formation process of cultural identity among the informants who had settled in the one cultural different with informant who had settled in both the culture and the informant who was never completely settled in the both culture. While the child's language development is affected by the communication within the family and in an environment where the child is interacting. The summary of this research is that the culture studied and taught when people are in a cultural environment and interact
\end{abstract}

ISSN: 2548-3242 (cetak), eISSN: 2549-0079 Website: http://jurnal.unpad.ac.id/manajemen-komunikasi 
with people from within the culture. So cultural identity and language development is influencedby the environment in which one lives.

Keywords: Culture identity, teen language, different culture marriage

Korespondensi: Yulia Citra Dewi. Fakultas Ilmu Komunikasi Universitas Padjadjaran, Jln. Raya Bandung-Sumedang KM 21 Jatinangor. Email: yuliacitrak@yahoo.com

\section{PENDAHULUAN}

"Gw sebenernya di Medan, gw kan besar, eh sebenernya gw ga besar di Medan juga, cuman pas gw remaja gw di Medan gitu. Jadi itu kayanya yang paling lekat sama gw. Keluarga dari Bokap gw juga yang tinggal di Sumatera Utara itu, berperilakunya itu juga ga kaya orang Arab juga, seperti orang melayu dan ya gitu gw merasa orang melayu ajah gitu. Susahlah ngejelasinnya, pokoknya gw ngerasa orang melayu gitu.",

Begitulah tanggapan Hafis (Wawancara 30 Juli 2012), salah satu informan dalam penelititan ini ketika peneliti bertanya mengenai budaya. Hafis yang adalah mahasiswa Fakultas Ilmu Komunikasi yang memilih menganggap dirinya sebagai bagian dari kebudayaan dimana dia tinggal dan dibesarkan. Hafis yang lahir dari keluarga percampuran budaya Sunda dan Jawa-Arab ini mengaku sebagai orang Melayu dan berkomunikasi dengan menggunakan bahasa dan logat Melayu karena dia lebih mengenal kebudayaan tersebut dibandingkan dengan dua kebudayaan yang diwariskan oleh ayah dan ibunya.

Walaupun orang tuanya berkebudayaan Sunda dan Jawa, tapi kebudayaan Melayulah yang melekat pada diri Hafis dan menjadikannya salah satu identitas diri Hafis. Hal ini menurutnya karena masa remaja dan awal pergaulan dengan temantemannya adalah dengan orang-orang dari lingkungan dengan budaya Melayu yang kental dan masih sangat menjunjung tinggi nilai-nilai dari kebudayaan Melayu tersebut.

Berbeda dengan Reagan, bocah laki-laki berusia 10 tahun yang bisa dibilang sebagai orang multi budaya (multy cultural person), karena dalam dirinya terdapat dua budaya subjektif yang berbeda. Terlahir dari keluarga pernikahan beda budaya SundaMinang, memungkinkan Reagan untuk berkomunikasi dengan dua bahasa atau tiga jika bahasa Indonesia di masukkan kepada kategori bahasa daerah. Reagan yang tinggal dengan ayah -Minang-, ibu -Sundamemakai tiga bahasa berbeda untuk berkomunikasi. Ketika berkomunikasi dengan ayahnya dia menggunakan bahasa Minang, ketika berkomunikasi dengan 
ibunya dia akan menggunakan bahasa Sunda dan sedikit campuran bahasa Indonesia.

Perilaku komunikasi Reagan dan Hafis menunjukkan bagaimana mereka menunjukkan identitas dirinya dalam proses komunikasi. Reagan akan menampilkan identitas diri yang berbeda-beda pada setiap percakapan. Ketika berkomunikasi dengan ayah, dia menggunakan identitas sebagai remaja dari suku Minang yang lancar berbahasa Minang, pada saat berkomunikasi dengan ibunya, dia memperlihatkan identitasnya sebagai remaja dari budaya Sunda yang lancar berbahasa Sunda. Begitupun pada saat ia berada dilingkungan, seperti ketika ia berinteraksi dengan teman atau lingkungannya dia akan menunjukkan identitas diri yang berbeda pula.

Jika melihat dari garis keturunan, orang seperti Hafis yang lahir dalam keluarga percampuran budaya Sunda dan Jawa akan otomatis menyandang status sebagai bagian dari kebudayaan Jawa karena kebudayaan Sunda dan Jawa sama-sama menganut sistem Patriartki, yaitu menurut pada garis keturunan ayah. Tapi dalam kenyataannya Hafiz menganggap dirinya bagian dari kebudayaan Melayu. Sedangkan orang seperti Reagan yang lahir dalam keluarga campuran Padang dan Sunda seharusnya tidak memiliki budaya. Melihat pada kebudayaan Minang yang menganut Matriarki, garis keturunan ibu. Dan Sunda yang menganut Partiarki, garis keturunan
Ayah. Akan tetapi Reagan memilih menyandang ke-dua kebudayaannya itu dengan sama rata.

Proses pencarian identitas adalah proses dimana seorang remaja mengembangkan suatu identitas personal atau sense of self yang unik yang berbeda dari orang lain (individuation).

Dalam psikologi perkembangan pembentukan identitas merupakan tugas utama dalam perkembangan kepribadian yang diharapkan tercapai pada akhir masa remaja. Pembentukan identitas sebenarnya sudah dimulai dari masa kanak-kanak, tetapi pada masa remaja ia menerima dimensidimensi baru karena berhadapan dengan perubahan-perubahan fisik, kognitif, dan relasional (Grotevant dan Cooper, 1998 dalam psikologi remaja, Ali:2000).

Identitas seorang anak sangat ditentukan oleh pola komunikasi dan pola asuh yang berlangsung dalam keluarga. Dimana seorang anak akan meniru dan melakukan hal-hal yang biasa dilihat terjadi dalam keluarganya. Pola asuh dan perilaku komunikasi orang tua menjadi cikal bakal terlahirnya perilaku komunikasi anak. Budaya dan interaksi dalam keluarga dan masyarakat sangat menentukan perilaku komunikasi tersebut.

Identitas dan perilaku komunikasi juga dipengaruhi oleh hubungan sosial kita dengan masyarakat. Hubungan sosial ini mula-mula dimulai dari lingkungan rumah 
sendiri, kemudian berkembang lebih luas lagi ke lingkungan sekolah, dan dilanjutkan kepada lingkungan yang lebih luas lagi, yaitu tempat berkumpulnya teman sebaya. Situasi kehidupan dalam keluarga berupa pola asuh orang tua, pada umumnya masih dapat diperbaiki oleh orang tua itu sendiri, tetapi situasi pergaulan dengan teman-teman sebayanya cendrung sulit diperbaiki.

Keluarga merupakan kelompok sosial pertama dalam kehidupan manusia dimana ia belajar dan menyatakan dirinya sebagai manusia sosial didalam hubungan interaksi dengan kelompoknya. Komunikasi yang berlaku dalam komunikasi kelompok, berlaku pula bagi interaksi kelompok keluarga, termasuk pembentukan normanorma sosial, internalisasi dari norma-norma sosial dan sebagainya. Dalam keluarga, manusia pertama-tama belajar memperhatikan keinginan-keinginan orang lain, belajar bekerjasama. Dengan kata lain remaja belajar memegang peranan sebagai makhluk sosial yang memiliki norma dan kecakapan-kecakapan tertentu dalam pergaulannya dengan orang lain.

Sebagaimana keluarga punya perangkat nilai dan pengharapan bagi anggota-angotanya, keluarga juga punya pengharapan-pengharapan atas komunikasi. Setiap keluarga memiliki pedoman-pedoman mengenai aturan-aturan komunikasi yang dapat dipahami.
Teknologi menyebabkan hubungan antarbudaya menjadi mudah, praktis, dan tidak dapat dihindarkan. Menurut Sihabudin (1998:54) cepat atau lambat akan terjadi pertukaran besar-besaran dalam kelompok yang dinamakan masyarakat yang diakibatkan oleh revolusi ilmu pengetahuan dan teknologi.

Komunikasi kultural atau komunikasi budaya pada dasarnya juga komunikasi antarpersona, tetapi ditambah dengan penekanan pada ciri-ciri budaya yang berbeda di antara partisipasinya, yang meliputi perbedaan bahasa, persepsi, sikap, nilai-nilai, dan pola berpikir.

Secara garis besarnya, intercultural communication atau komunikasi antarbudaya itu terjadi apabila suatu budaya memproduksi pesan untuk disampaikan kepada anggota dari budaya lain. Atau lebih jelasnya, komunikasi antar budaya melibatkan interaksi antara orang yang memiliki persepsi budaya dan sistem simbol yang berbeda, cukup untuk merubah aktivitas komunikasi (Samovar. 2009:12).

Karena cara kita berkomunikasi sebagian besar dipengaruhi oleh kultur, orang-orang dari kultur bebeda akan berkomunikasi secara berbeda. Artinya, budaya dan komunikasi tidak dapat dipisahkan, karena tidak hanya menentukan siapa, tentang apa, dan bagaimana komunikasi berlangsung, tetapi budaya juga turut menentukan bagaimana orang 
menyandi pesan; makna yang ia miliki untuk pesan dan kondisi-kondisi untuk mengirim, memperhatikan, dan menafsirkan pesan. Sebenarnya, seluruh perbendaharaan perilaku kita sangat tergantung pada budaya kita dibesarkan (Muchtar, Koswara, Setiaman, 2016:113).

Sebagai orang Indonesia, sudah terbiasa dengan perbedaan-perbedaan khususnya di bidang budaya. Dengan masyarakat dari suatu budaya yang berpindah dan hidup bersama dengan masyarakat dari budaya lain di suatu daerah tertentu, memungkinkan sekali untuk adanya pencampuran keturunan (mixed heritage).

Perkawinan campuran adalah perkawinan antara orang-orang indonesia sendiri yang berasal dari suku bangsa atau daerah yang berlainan dan hidup dalam berbagai lingkungan hukum (Gautama, 1994 : 4). Misalnya seperti kasus yang terjadi dalam keluarga Reagan, ayah Reagan adalah orang Minang (Padang) asli yang lahir dan dibesarkan didaerah dan lingkungan kebudayaan Minang kabau dan kemudian merantau ke kota Bandung. Di Kota Bandung dia bertemu dengan ibu Reagan yang berkebudayaan Sunda, yang lahir dan dibesarkan dalam lingkungan kebudayaan Sunda. Setelah beberapa waktu menjajaki hubungan dan menjalani proses pencocokan, kemudian mereka menikah. Inilah salah satu contoh pernikahan campuran.
Proses menjajaki hubungan dan proses pencocokan ini merupakan proses asimilasi dimana kedua belah pihak mencoba untuk mengurangi perbedaan-perbadaan yang terjadi karena budaya dan kebudayaan tempat mereka dilahirkan yang berbeda satu sama lain. Kedua belah pihak mencoba untuk mencari persamaan dalam kepentingankepentingan dan tujuan-tujuan mereka agar selaras dengan keinginan kedua belah pihak.

Pada keluarga pernikahan beda budaya ini akan mengalami proses adaptasi budaya dan nilai-nilai yang mereka bawa dari budaya masing-masing, yang nantinya akan di ajarkan atau diturunkan kepada anakanaknya dan membentuk dan mempengaruhi identitas budaya dan perilaku komunikasi remaja.

Dari penjabaran konteks penelitian diatas, maka peneliti tertarik untuk mengamati bagaimana identitas budaya yang dibangun oleh remaja yang terlahir dari keluarga pernikahan beda budaya

Berdasarkan penjabaran konteks penelitian yang telah dipaparkan mengenai "budaya adalah komunikasi dan komunikasi adalah budaya" serta pola-pola hubungan dan siklus perilaku dalam keluarga yang menyatakan "setiap anggota keluarga mempengaruhi orang-orang lainnya dan pada gilirannya dipengaruhi oleh mereka”. Maka peneliti tertarik untuk melakukan penelitian tentang "Bagaimana proses pembentukan 
identitas budaya remaja dari keluarga pernikahan beda budaya?"

Secara spesifik, dalam penelitian ini akan diperoleh penjelasan mengenai:

a. Proses pembentukan identitas budaya remaja dari keluarga pernikahan beda budaya.

b. Penggunaan bahasa oleh remaja dari keluarga pernikahan beda budaya.

\section{METODE PENELITIAN}

Metode penelitian yang digunakan dalam penelitian ini yaitu dengan menggunakan metode penelitian kualitatif. Dalam buku Qualitative Inquiry and Research Design, penelitian kualitatif adalah sebuah proses penyelidikan, pemahaman didasarkan pada perbedaan tradisi-tradisi metodologis pada penelitian yang menjelaskan permasalahan sosial atau manusia. Peneliti menjelaskan sebuah tempat, gambaran holistik, analisis kata-kata, laporan secara detail menurut sudut pandang informan dan perilaku studi dalam setting ilmiah (Natural Setting) (Creswell, 1998 : $15)$.

Bodgan dan Taylor mendefinisikan metodologi kualitatif sebagai prosedur penelitian yang menghasilkan data deskriptif berupa kata-kata tertulis atau lisan dari orang-orang dan perilaku yang dapat diamati. Menurut mereka, pendekatan ini diarahkan pada latar dan individu tersebut secara holistik (utuh). Jadi, organisasi kedalam variabel atau hipotesis, tetapi perlu memandangnya sebagai bagian dari sesuatu keutuhan. Kemudian Kirk dan Miller mendefenisikan bahwa penelitian kualitatif adalah tradisi tertentu dalam ilmu pengetahuan yang secara fundamental bergantung dari pengamatan pada manusia baik dalam kawasannya maupun peristilahannya (Moleong, 2007 : 4).

Secara spesifik, metode yang digunakan adalah fenomenologi. Menurut Husserl, segala sesuatu yang ada di dunia ini dan diterima oleh manusia melalui inderainderanya hanya dapat diketahui melalui kesadaran. Dengan kesadaran, manusia dapat memaknai segala hal yang diterimanya sebagai suatu realitas.

Oleh sebab itu kegiatan manusia dilakukan dalam dunia kehidupan (sehari hari) yang diterima begitu saja dan kemudian menganggap bahwa mereka mengalami hal yang sama tidak bisa diterima. Apabila dunia kehidupan (sehari-hari) seseorang membentuk kesadarannya dan mempengaruhi tingkah lakunya, bagaimana pengetahuan obyektif tentang tingkah laku dan organisasi manusia menjadi mungkin? Ini menjadi pertanyaan yang menyebabkan Husserl mengkritik ilmu alam dan ilmu positif.

Pengumpulan data menggunakan wawancara mendalam dan observasi partisipatori. Wawancara digunakan sebagai 
teknik pengumpulan data apabila peneliti ingin melakukan studi pendahuluan untuk menemukan permasalahan yang harus diteliti tetapi juga apabila peneliti ingin hal-hal dari responden yang lebih mendalam. Teknik pengumpulan data ini mendasarkan diri pada laporan tentang diri sendiri atau self report, atau setidak-tidaknya pada pengetahuan atau keyakinan pribadi. (Sugiono, 2005:72). Sementara itu observasi partisipatori adalah pengamatan langsung melalui partisipasi aktif yang dilakukan terhadap subjek penelitian, yaitu remaja yang merupakan anak dari keluarga penikahan beda budaya.

\section{HASIL DAN PEMBAHASAN}

\section{a. Pembentukan Identitas Budaya}

Penelitian ini memperlihatkan bahwa pembentukan identitas budaya seorang remaja yang berasal dari keluarga percampuran budaya terbagi menjadi tiga kategori:

1. Identitas budaya pada remaja dari keluarga pernikahan beda budaya yang pernah tinggal di salah satu lingkungan kebudayaan yang dimilikinya. Seperti informan 1, 2 dan 4. Informan 1, Belajar tentang kebudayaan dan mengenal kebudayaan Sunda ketika sudah menetap di Jatinangor-Bandung dan mengunjungi neneknya di Bandung. Sebelumnya ketika sekolah dan tinggal di Tanggerang, orang tua tidak mengajarkan tentang kebudayaan karena mereka tinggal di tempat dengan budaya heterogen dan tidak pada lingkungan dalam salah satu budaya. Jadi informan tidak merasa perlu untuk mengenal kebudayaan Sunda ataupun Melayu. Tetapi merasa bagian dari kebudayaan Sunda karena sudah mengenal dan tinggal di Bandung. Sedangkan Informan 2, merasa menjadi orang Jawa karena di lahirkan dan dibesarkan dalam lingkungan kebudayaan Jawa. Walaupun orang tua tidak pernah mengajarkan tentang kebudayaan di rumah, namun pergaulan dengan teman serta lingkungan tempat tinggal adalah lingkungan budaya Jawa. Informan 4, merasa bagian dari budaya Sunda karena menurut pada garis keturunan ayah maka dia mengikuti kebudayaan ayahnya. Ditambah lagi karena dia sudah tinggal di Sukabumi (Sunda) maka dia bergaul dengan kebudayaan Sunda. Informan dan orang tua menganggap akan sangat lucu ketika dia belajar kebudayaan Betawi sementara dia tinggal dan menetap di lingkungan berbudaya Sunda.

Akan tetapi berbeda dengan Informan 3. Informan 3 yang seharusnya memilih identitas sebagai orang Jawa menurut garis keturunan. Atau seharusnya memilih budaya Sunda sebagai budaya alternatifnya malah merasa dirinya bagian dari kebudayaan Melayu karena sebagian masa pertumbuhan sampai remajanya di habiskan dalam lingkungan dengan kebudayaan Melayu yang kental. Ditambah lagi orang tua tidak pernah mengajarkan tentang kebudayaan. Walaupun 
pernah tinggal di lingkungan Sunda, pernah tinggal di salah satu lingkungan informan tetap memilih Melayu karena dia kebudayaan yang dimilinya. Seperti hanya tinggal sebentar di Sunda dan dalam Informan 7. Merasa sebagai orang Bekasi waktu yang singkat.

2. Identitas budaya pada remaja dari keluarga pernikahan beda budaya yang pernah tinggal di kedua lingkungan kebudayaan yang dimilikinya. Seperti Informan 5, yang merasa bagian dari kedua kebudayaan (Bengukulu-Sunda) karena telah menetap dan belajar kedua kebudayaan tersebut baik disekolah maupun memperhatikan di lingkungan. Informan lahir dan menetap di Bengkulu sampai menginjak kelas 2 SMP. Jadi sudah terbiasa dengan kebudayaan Bengkulu. Kemudian informan pindah ke Serang dengan lingkungan berkebudayaan Sunda. Maka sekarang dia juga merasa bagian dari suku Sunda. Sedengkan Informan 6, Merasa bagian dari kedua kebudayaan (BatakMinang). Informan Sangat mengerti tentang kebudayaan Batak dan memiliki keluarga dengan kebudayaan yang kental karena kakeknya merupakan kepala suku di tempat dia tinggal. Walaupun awalnya tidak tertarik mempelajari tentang budaya Minang karena apa gunanya ketika dia tinggal di Medan dengan kebudayaan Batak. Tapi setelah pindah dan menuntut ilmu di Padang, dia mulai tertarik dan mempelajari kebudayaan Minang.

3. Identitas budaya pada remaja dari keluarga pernikahan beda budaya yang tidak karena lahir dan tinggal di Bekasi. Walaupun informan tertarik untuk mempelajari tentang kedua kebudayaan orang tuanya, dia tidak memiliki kesempatan untuk belajar karena lingkungan tempat tinggalnya bukanlah lingkungan dengan mengedepankan kebudayaan. Orang tua pernah mengajarkan beberapa hal tentang kebudayaan sebelumnya, tetapi sangat sedikit.

\section{b. Pemilihan bahasa}

Penelitian ini memperlihatkan hasil pembahasan dari tema pemilihan bahasa yang di bagi berdasarkan aliran nativisme dan empirisme memperlihatkan Informan 1 dan 7. Secara garis besar memakai bahasa Indonesia di rumah maupun di lingkungan pertemanan. Karena orang tuanya berkomunikasi dengan menggunakan bahasa Indonesia di rumah dan lingkungannya juga berkomunikasi dengan menggunakan bahasa Indonesia. Waluapun informan 1 sedikit mengerti ketika mendengar orang berbicara dalam bahasa Sunda dan Melayu, tetapi informan tidak bisa dalam pengucapan atau ketika berbicara. Begitu pula dengan informan 7. Karena tidak pernah tinggal di lingkungan dimana bahasa daerah dipakai, walaupun terkadang ibunya mengajak berbicara ketika sedang ada keluarga lain dari budaya Jawa namun dia hanya mengerti 
bahasa tersebut tapi tidak bisa mengucapkan dan berbicara dengan bahasa tersebut.

Bagi Informan 2 dan 4. Informan 2 Memakai bahasa Indonesia ketika berkomunikasi dengan orang tuanya karena di rumah orang tua berkomunikasi dengan menggunakan bahasa Indonesia. Tapi memakai bahasa Jawa ketika berkomunikasi dengan teman-teman karena semua temannya berasal dari suku Jawa. Alasan kenapa bahasa Jawa tidak dipakai di rumah adalah karena informan tidak terlalu mengerti bahasa Jawa halus yang dipakai ketika bicara dengan orang yang lebih tua. Sama halnya dengan informan 2, informan 4 juga memakai bahasa Indonesia ketika berkomunikasi dengan orang tua dirumah dan memakai bahasa Sunda ketika berkomunikasi dengan teman-temannya. Hal ini terjadi karena orang tua tidak mengajarkan untuk memakai bahasa daerah dirumah. Walaupun terkadang informan memakai bahasa Sunda untuk berbicara dengan ayahnya.

Sedangkan Informan 5. Memakai bahasa Bengkulu baik dirumah maupun dengan teman-teman dan lingkungannya ketika masih tinggal di Bengkulu. Tapi ketika pindak ke Serang dia menggunakan bahasa Indonesia dan lama kelamaan bahasa Bengkulu luntur karena jarang sekali di pakai. Sedangkan untuk bahasa Sunda atau bahasa Serang sendiri informan tidak bisa mengerti maupun berbicara dengan bahasa tersebut karena di lingkungan tempat tinggal maupun dilingkungan pertemanannya memakai bahasa Indonesia untuk berkomunikasi.

Informan 6. Bisa memakai kedua bahasa (Batak dan Minang). Dirumah informan berkomunikasi menggunakan bahasa Batak dan terkadang menggunakan bahasa Minang dengan ibu dan kakaknya yang juga pernah tinggal di Padang dan fasih menggunakan bahasa tersebut. Sedangkan dalam pergaulan, dia berbicara Batak ketika dengan teman yang berasal dari medan dan memakai bahasa Minang ketika berkmunikasi dengan teman yang berasal dari Padang.

Informan 3. Bisa memakai bahasa Melayu, dan Sunda karena seringnya berpindah-pindah. Dirumah memakai bahasa Indonesia ketika berkomunikasi dengan orang tuanya karena orang tua tidak mencontohkan untuk memakai bahasa daerah dan tidak mengajarkan pula bahasa daerah di rumah. Sedangkan di lingkungan petemanan mengaku fleksibel menggunakan bahasa Sunda ketika dengan teman Sunda tapi tetap berlogat Melayu karena bahasa Melayulah yang paling melekat pada dirinya.

\section{SIMPULAN}

Proses Pembentukan identitas budaya remaja dari keluarga pernikahan beda budaya menghasilkan simpulan bahwa proses pembentukan identitas dipengaruhi oleh 
significant others yaitu keluarga dan teman, baik teman di lingkungan rumah maupun teman di sekolah, dan generalized others yaitu lingkungan masyarakat. Dari penelitian ini disimpulkan bahwa dalam keluarga pernikahan beda budaya, orang tua jarang sekali mengajarkan tentang kebudayaan. Kebudayaan dipelajari hanya ketika berada dalam lingkungan dimana kebudayaan tersebut ada.

Biasanya anak akan belajar kebudayaan dari interaksi dengan lingkungan baik itu teman bermain, sekolah ataupun masyarakat di sekitar budaya di mana dia tinggal dan berinteraksi yang kemudian menentukan identitas budayanya. Identitas budaya seseorang tergantung pada lingkungan dimana dia tinggal.

Pemilihan identitas budaya tidak hanya dipengaruhi oleh garis keturunan. Pilihan pribadi dan pengaruh pergaulan juga menjadi pokok utama dalam pertimbangan identitas budaya.

Pemilihan bahasa yang digunakan oleh remaja yang berasal dari keluarga pernikahan beda budaya dijelaskan dalam dua aliran perkembangan. Perkembangan bahasa dilihat berdasarkan aliran nativisme dan aliran empirisme.

\section{DAFTAR PUSTAKA}

Ali Mohammad, Mohammad Asrori. 2009. Psikologi Remaja: Perkembangan Peserta Didik. Jakarta. Bumi Aksara
Creswell, John. W. 1998. Qualitative Inquiry and Research Design : Choosing Among Five Tradition. London : Saga Publication.

Kuswarno, Engkus. 2009. Metode Penelitian Komunikasi: Fenomenologi. Bandung: Widya Padjadjaran.

Liliweri, Alo. 2007. Makna Budaya dalam Komunikasi Antarbudaya. Jogyakarta: LkiS Pelangi Aksara

Muchtar, Khoiruddin, Iwan Koswara, Agus Setiaman. 2016. Komunikasi Antarbudaya dalam Perspektif Antropologi. Jurnal Manajemen Komunikasi, Volume 1 Nomor 1 Halaman 113-123

Sihabudin, Ahmad. (2011). Komunikasi Antar Budaya: Satu perspektif Multi dimensi. Jakarta: Bumi Aksara. 